\title{
Review
}

\section{Outcomes after robot-assisted laparoscopic radical prostatectomy}

\author{
Declan G. Murphy ${ }^{1}$, Benjamin J. Challacombe ${ }^{2}$, Anthony J. Costello ${ }^{2}$ \\ ${ }^{I}$ The Urology Centre, Guy's \& St. Thomas'NHS Foundation Trust, London SE1 9RT, UK \\ ${ }^{2}$ Department of Urology, Royal Melbourne Hospital, Melbourne VIC 3054, Australia
}

\begin{abstract}
Robot-assisted laparoscopic radical prostatectomy (RALRP) using the da Vinci surgical system is now in widespread use in many countries where economic conditions allow the installation of this expensive technology. Controversy has surrounded the procedure since it was first performed in 2000, with many critics highlighting the lack of evidence to support its use. However, despite the lack of level I evidence, many large studies of patients have confirmed that the procedure is feasible and safe, with low morbidity. Available longer-term oncological data seem to show that outcomes from the robotic approach at least match those of traditional open radical prostatectomy. Functional outcomes also seem satisfactory, although randomized controlled trials are lacking. This paper reviews the current status of RALRP with respect to perioperative data and complications and oncologic and functional outcomes.
\end{abstract}

Asian Journal of Andrology (2009) 11: 94-99. doi: 10.1038/aja.2008.10; published online 1 December 2008.

Keywords: da Vinci, laparoscopic, outcomes, prostate cancer, radical prostatectomy, robotic

\section{Introduction}

Owing to the rapid dissemination of da Vinci surgical systems (Intuitive Surgical, Mountain View, CA, USA) across the United States, the majority of radical prostatectomies in that country are now performed using robotic assistance. The incidence of prostate cancer has increased, and stage migration has resulted in a higher proportion of localized cases. As radical prostatectomy remains the only intervention proven to have a survival advantage when compared with surveillance in patients with localized prostate cancer, surgery is likely to remain the preferred option for many patients [1]. However, traditional concerns regarding the morbidity associated with the open surgical approach have led patients to seek a 'less invasive' approach. A number of claims have been made for the benefit of robotassisted laparoscopic radical prostatectomy (RALRP)

Correspondence to: Mr Declan G. Murphy, The Urology Centre, Guy's \& St. Thomas' NHS Foundation Trust, Great Maze Pond, London SE1 9RT, UK.

Fax: +44-20-7188-6787_E-mail: decmurphy@doctors.net.uk

Received: 7 September 2008 Accepted: 13 September 2008

Published online: 1 December 2008. over open radical prostatectomy (ORP); however, there is minimal evidence from randomized controlled trials to confirm such claims. Nevertheless, in many countries the opinions of patients and surgeons have been swayed by non-randomized evidence and other market forces, and RALRP has now become the preferred approach for the management of localized prostate cancer in many regions.

When assessing the outcome data of radical prostatectomy for the management of localized prostate cancer, three key domains must be considered. The 'trifecta' of outcome measures proposed by Bianco et al. [2] reflects the fine balancing act between cancer control and quality-of-life determinants such as continence and potency, and these outcome measures must all be considered when evaluating any intervention for the management of localized prostate cancer. The lack of level I evidence makes this task somewhat difficult; yet a large amount of cohort-based evidence, from which we can evaluate the outcomes, has now been published.

Although the debate surrounding the cost effectiveness of the robotic approach continues, this paper reviews the current status of RALRP, particularly with respect to perioperative data and oncological and functional outcomes. 


\section{Evolution of RALRP from 2000 to 2009}

The arrival of RALRP was preceded by an interesting decade during which laparoscopic radical prostatectomy (LRP) was developed. Although LRP was first performed in the United States in 1992, the procedure was considered 'too difficult' and without likely benefit, and further development of the procedure in the United States was effectively stalled [3]. However, in Europe, interest in LRP continued and the procedure enjoyed a new wave of popularity following the work by Guillonneau et al. [4] in 1999. Outcome data from centres of excellence showed cancer control rates, urinary continence and potency rates comparable to those of ORP, but with the additional benefit to patients of a minimally invasive approach $[5,6]$. However, LRP is a difficult procedure with a long learning curve, and concerns over this and long-term oncologic efficacy resulted in poor uptake of this procedure, particularly in the United States.

In contrast is the initial report of RALRP and the subsequent wave of interest in the procedure in the United States [7]. Although operating times were initially long [8, 9], they were reduced to less than $3 \mathrm{~h}$ in many series, with operating times of less than $2 \mathrm{~h}$ in high-volume centres [ $[10$, 11]. Long before any significant outcome data had been reported, many centres rushed to install the associated technology and develop an RALRP programme. The number of RALRPs rose from 766 in 2002 to 48000 in 2007, and RALRPs accounted for the majority of radical prostatectomies performed in the United States. So great was the demand for robotic surgery that many large centres with world-class ORP programmes developed RALRP programmes largely due to market pressure. The situation in Europe was different as a result of less favourable economic climates for the installation of this expensive technology, as well as greater availability of LRP. Similar financial constraints affected the development of robotic surgery programmes in Austral-Asia, but in these regions the number of da Vinci installations and robotic surgery procedures performed has also increased dramatically [12].

\section{The transition from open to robotic surgery}

There is no doubt that part of the initial enthusiasm for RALRP was driven by experienced open surgeons wishing to make a transition to a minimally invasive approach without having to negotiate the steep LRP learning curve. Some of the early literature regarding RALRP focused on this issue and has subsequently become highly cited as a compelling attraction of robotic technology. Ahlering et al. [13] published their experience of transition from open to robotic surgery in 45 cases and reported that the learning curve to 4-h proficiency was achieved in just 12 cases. Positive surgical margin (PSM) rates in this series were $35.5 \%$. A number of early publications from Detroit documented their initial experience in moving from open to robotic surgery and reported a similar enthusiasm for the transition [14-16]. Operating times averaged $4.8 \mathrm{~h}$ for the first 30 RALRPs, but complication rates and PSMs were equivalent to those in their ORP series. Subsequent reports from this group showed dramatic improvements in all parameters related to RALRP [17].

The Melbourne group reported their initial experience of 150 RALRPs when transitioning from open surgery with no prior laparoscopic experience [18]. Operative times dropped from a mean of 292 min for the first 20 cases to 191 min for 130150 cases. Morbidity and PSMs remained low when compared with the ORP experience.

Centres experienced in LRP have also documented their experiences in transitioning to RALRP and reported equivalent outcomes [19]. The most striking advantages in terms of a learning curve are likely to exist in centres transitioning from open surgery. However, most open surgeons who are interested in RALRP will have made their transition by now, and the next generation of robotassisted surgeons will be fellowship trained or will have extensive laparoscopic experience and can avoid the learning curve issues.

\section{Outcome data}

\subsection{Oncological data}

Evaluation of oncological outcome includes overall survival, disease-specific survival and biochemical recurrence-free survival (BCRFS), defined as a prostate-specific antigen (PSA) $<0.2 \mathrm{ng} \mathrm{mL}^{-1}$. However, because RALRP series are relatively immature when compared with the ORP series in which 15-year outcome data have been reported [20], BCRFS and PSM status are often used as surrogates for cancer control when evaluating oncologic efficacy. Considerable variation exists in the PSM rates reported in the RALRP literature. Early studies reported PSMs of $13 \%-35 \%[13,21]$, and contemporary studies also show relatively high PSMs in the early experience of some centres [22]. As the more experienced centres have accumulated large numbers of cases, the reported margin rates for RALRP have been reduced to overall PSM rates of $<15 \%$ and pT2 PSM rates of $<10 \%$, which seem to be the minimum standard to which centres should aspire $[10$, $11,23,25]$.

However, as with ORP or LRP, there is certainly a learning curve to be negotiated before PSM rates reach the levels published by the large centres. Atug et al. [26] reported on their initial series of 140 patients undergoing RALRP and stratified PSMs as their experience increased. PSMs dropped from $45.1 \%$ in the first 33 patients to 
$11.7 \%$ in the last 34 patients. This suggests that the learning curve for RALRP is not as short as some authors have proposed.

Long-term oncological results are not yet available. The largest series of RALRP, from the Henry Ford Centre in Detroit involving 2766 patients with a follow-up of up to 5 years, has been reported by Badani et al. [27]. The proportions of patients in low-, intermediate- and highrisk categories were $69.1 \%, 22.7 \%$ and $8.2 \%$, respectively. The pT2 PSM rate was $13 \%$, and the BCRFS with a mean follow-up of 25.8 months was $92.7 \%$. In another large series with a minimum follow-up of 12 months, Murphy et al. [23] reported on 400 patients with a mean follow-up of 23.3 months. The proportions of patients in low-, intermediate- and high-risk categories were $36.5 \%, 50.25 \%$ and $13.25 \%$, respectively, which represent considerably less favourable tumour characteristics than those reported in Badani's series. The pT2 PSM rate was $9.6 \%$, with a BCRFS of $86.6 \%$.

\subsection{Continence outcome}

The objective evaluation of urinary continence outcomes after radical prostatectomy remains hindered by the lack of standardization of outcome reporting. Although validated tools exist, these are not in popular use, and the introduction of terms such as 'socially dry' and 'security liner' has somewhat obscured the issue of true continence [11]. In addition, it is accepted that patient- and surgeonreported outcomes vary considerably; yet surgeon-reported outcomes are the most commonly used variable.

By using the criterion of no pads or one security liner to define continence, the proportion of patients reporting being 'dry' at 12 months following RALRP is 90\%-95\% (Table 1). Using similar criteria, the same proportion of patients is also considered dry following ORP and LRP $[2,28]$. It is not possible to say whether any particular approach to radical prostatectomy delivers better continence outcomes without prospective randomized trials, although, based on current non-randomized data, the outcomes of these treatments seem equivalent.

There is increasing interest in techniques to help patients achieve early continence. Borrowing techniques previously developed for ORP and reconstruction of anterior and/or posterior support structures may increase early continence, although no randomized evidence exists to establish that these modifications make a difference [29].

\subsection{Potency outcome}

As with the evaluation of urinary continence after radical prostatectomy, it is difficult to evaluate the potency outcomes following RALRP because of the variability of definitions used to determine potency. The most commonly used criteria to define potency include a sexual health inventory for men (SHIM) score of 21 or greater and a score of at least 2 on Question 2 of the SHIM questionnaire ('When you had erections with stimulation, how often were your erections hard enough for penetration?'). Additional confounding factors include the type of nerve-sparing technique employed, whether nerve-sparing is unilateral or bilateral and the use of adjuvant medications such as phosphodiesterase-5 (PDE-5) inhibitors.

Considerable debate has developed over novel nervesparing modifications such as the 'Veil of Aphrodite' technique [30]. The 'standard' technique releases the neurovascular bundle from the posterolateral groove in the inter-fascial plane. Menon et al. [31] have proposed a higher lateral incision of the lateral prostatic fascia and an intra-fascial approach to release the neurovascular bundle, presuming that cavernosal nerves lie high in the lateral prostatic fascia. Their outstanding report of $97 \%$ potency in men undergoing this technique attracted much

Table 1. Summary of operative and outcome data from the selected RALRP series.

\begin{tabular}{|c|c|c|c|c|c|c|c|c|c|c|}
\hline Author & $n$ & $\begin{array}{l}\text { Mean } \\
\text { PSA } \\
(\mathrm{ng} / \mathrm{mL})\end{array}$ & $\begin{array}{l}\text { Mean } \\
\text { operative } \\
\text { time (min) }\end{array}$ & $\begin{array}{l}\text { Mean } \\
\text { blood } \\
\text { transfusion } \\
(\%)\end{array}$ & $\begin{array}{l}\text { Mean } \\
\text { hospital } \\
\text { stay } \\
\text { (days) }\end{array}$ & $\begin{array}{l}\text { Overall } \\
\text { positive } \\
\text { surgical } \\
\text { margins } \\
\text { (pT2 } \\
\text { margins) } \\
(\%)\end{array}$ & $\begin{array}{l}\text { Continence } \\
(\leq 1 \mathrm{pad} / \\
\text { day })(\%)\end{array}$ & $\begin{array}{l}\text { Potency } \\
(\%)\end{array}$ & $\begin{array}{l}\text { Mean } \\
\text { follow- } \\
\text { up } \\
\text { (months) }\end{array}$ & $\begin{array}{l}\text { BCRFS } \\
(\%)\end{array}$ \\
\hline Joseph et al. [25] & 325 & 6.6 & 130 & 1.3 & 1 & 96 & $13(9.9)$ & 70 & $\mathrm{~N} / \mathrm{R}$ & $\mathrm{N} / \mathrm{R}$ \\
\hline Patel et al. [10] & 500 & 6.9 & 130 & 0 & 1.1 & 95 & $9.4(2.5)$ & 78 & 9.7 & 95 \\
\hline Zorn et al. [41] & 300 & $\mathrm{~N} / \mathrm{R}$ & 282 & 1.7 & 1.4 & 90.2 & $20.9(15.1)$ & 80 & 17.3 & 93.1 \\
\hline Badani et al. [27] & 2766 & 6.4 & 154 & 1.5 & 1.1 & 93 & N/R (13) & 79.2 & 25.8 & 92.7 \\
\hline Mottrie et al. [24] & 184 & 8.7 & 171 & 0.5 & & 95 & $15.7(2.5)$ & 70 & 6 & 94.1 \\
\hline Murphy et al. [23] & 400 & 8.5 & 186 & 1.5 & 2.5 & 91.4 & $19.2(9.6)$ & 64 & 23 & 86.6 \\
\hline
\end{tabular}

Abbreviations: N/R, not recorded; RALRP, robot-assisted laparoscopic radical prostatectomy; BCRFS, biochemical recurrence-free survival 
attention at the time of publication [31]. In this study, 58 men undergoing RALRP for low-risk prostate cancer were divided into two groups: 23 men who underwent RALRP using the standard nerve-sparing technique and 35 men who underwent RALRP with preservation of the lateral prostatic fascia, the Veil of Aphrodite technique. When men using PDE-5 inhibitors were included, 17 of 23 (74\%) men in the standard technique group and 34 of 35 (97\%) in the Veil of Aphrodite group achieved erections strong enough for sexual intercourse. However, a further report of 154 men from the same institute undergoing RALRP using the Veil technique described a rate of recovery of normal erections (SHIM > 21) at 12 months of only $71 \%$ [32]. When men using PDE-5 inhibitors were excluded, the number dropped to $26 \%$. The researchers noted that $96 \%$ of these men reported having had intercourse in the previous 12 months despite the lack of 'normal' erections in a significant proportion of them. However, these numbers have not been replicated in other series, and concerns exist regarding the risks of PSMs with intra-fascial dissection [33]. Data available at an experienced laparoscopic centre in the UK suggest that the Veil technique potency results are not easy to replicate. Merilees et al. [34] performed bilateral 'curtain dissection' of the lateral prostatic fascia in 137 men undergoing extraperitoneal LRP for localized prostate cancer. They compared this group with 137 matched patients who had previously undergone LRP using the standard nerve-sparing technique. At a 12-month follow-up, the potency rate in the curtain dissection group was $68.4 \%$ vs. $67.2 \%$ in the standard technique group.

At present, the best anatomical and clinical evidence suggests that use of the standard nerve-sparing technique for RALRP produces potency rates of $64 \%-80 \%$ (see Table 1), and little evidence exists to recommend the Veil technique [35]. On the other hand, the avoidance of thermal energy during nerve sparing has been shown to improve potency outcomes regardless of the technique employed [36].

\section{Complications of RALRP}

The complications of RALRP may relate to laparoscopic access, the radical prostatectomy itself or technical problems related to the robot. The outcome data of many centres have focused on perioperative results and oncologic and functional outcome, with little comment regarding complications. However, there is a welcome trend towards adopting validated classification systems for reporting complications [37]. The Clavien system grades complications from I to V. Grade I indicates any deviation from the normal postoperative care plan; grade II complications require medical intervention; grade III requires surgical or radiological intervention; grade IV is a life-threatening complication requiring intensive therapy unit (ITU) management; and grade $\mathrm{V}$ is death. Two papers focused entirely on complications relating to RALRP $[38,39]$, and two other papers $[23,27]$ recommended the adoption of the Clavien system for reporting complications. Table 2 summarizes the findings from these publications with respect to complications.

Death is an extremely rare occurrence during or after RALRP. Access-related complications occur in less than $0.5 \%$ of RALRPs and include vascular and bowel injury. Bowel injury may involve the small bowel or rectum and includes rectal injury during dissection $(0 \%-1.25 \%)$, and inadvertent small bowel or colonic perforation $(<1 \%)$. Significant blood loss is much less common during RALRP than during ORP, and transfusion rates vary from $0 \%$ to $2.5 \%$. Bladder neck contractures occur in $0.5 \%-3.7 \%$ of cases.

Robot malfunction is reported in $0.4 \%-3 \%$ of cases [ 40 -42] and may lead to conversion to ORP or LRP if a spare robot is not available to continue the case.

\section{Comparisons with open series}

There are no large randomized, controlled trials comparing RALRP with ORP and/or LRP. Comparisons

Table 2. Complications of RALRP.

\begin{tabular}{|c|c|c|c|c|}
\hline Complication & $\begin{array}{c}\text { Badani et al. [27] } \\
\quad(n=2766)\end{array}$ & $\begin{array}{l}\text { Hu et al. }[38] \\
\qquad(n=322)\end{array}$ & $\begin{array}{l}\text { Fischer et al. [39] } \\
\qquad(n=210)\end{array}$ & $\begin{array}{l}\text { Murphy et al. [23] } \\
\qquad(n=400)\end{array}$ \\
\hline Overall complications & 12.2 & 22.6 & 26 & 15.75 \\
\hline Clavien III or greater & 0.6 & 2.7 & 8.5 & 5.25 \\
\hline Death & $<0.01$ & 0 & 0 & 0 \\
\hline Neuropraxia & $\mathrm{N} / \mathrm{R}$ & 0 & $\mathrm{~N} / \mathrm{R}$ & $\mathrm{N} / \mathrm{R}$ \\
\hline Urine leak & $\mathrm{N} / \mathrm{R}$ & 7.5 & 6.5 & 4.5 \\
\hline Bowel injury & $\mathrm{N} / \mathrm{R}$ & 0.6 & 1.5 & 1.2 \\
\hline Anastomotic stricture & $\mathrm{N} / \mathrm{R}$ & 0.6 & 0.5 & 3.7 \\
\hline Thromboembolic event & $\mathrm{N} / \mathrm{R}$ & 0.6 & $\mathrm{~N} / \mathrm{R}$ & $\mathrm{N} / \mathrm{R}$ \\
\hline Robot malfunction & 0.2 & 0.6 & 1.0 & N/RA \\
\hline
\end{tabular}

Abbreviations: N/R, not recorded; RALRP, robot-assisted laparoscopic radical prostatectomy. 
rely on level II and level III evidence from non-randomized and cohort studies.

Tewari et al. [43] compared their first 200 RALRPs with 100 consecutive ORPs and showed that operative times were similar once the learning curve was completed. The RALRP group performed better in terms of blood loss, transfusion requirements, postoperative pain and hospitalization time. Ahlering et al. [44] reported similar findings comparing their first 60 RALRPs with their open series. However, in a similar non-randomized study, Webster et al. [45] reported no differences in hospital stay and postoperative analgesia requirements between the RALRP and ORP groups. They showed a significant difference in blood loss $(191 \mathrm{~mL} v s .664 \mathrm{~mL}, P<0.001)$ in favour of the robotic group, but no difference in duration of hospitalization $[46,47]$.

O'Malley et al. [48] compared their previous 102 ORPs with their first 102 RALRPs performed by the same surgeon and noted a reduction of PSMs from 26.4\% to $13.7 \%$ even though the senior surgeon had no prior laparoscopic experience.

As part of a single-centre series of 1747 radical prostatectomies (open and robot-assisted), Smith et al. [49] compared the surgical margin status of 200 RALRPs with 200 ORPs. The overall PSM rate was significantly lower in the RALRP group compared with the ORP group (15\% vs. $35 \%, P<0.001)$, as was the PSM rate for pT2 tumours $(9.4 \%$ vs. $24.1 \%, P<0.001)$. The ORP group had slightly higher-risk tumour characteristics, which may have influenced these outcomes.

\section{$7 \quad$ The learning curve issue}

The learning curve of radical prostatectomy, and that of RALRP in particular, has received much attention in recent years. One of the proposed attractions of the robotassisted approach is that it lessens the difficulty associated with non-robotic LRP, reducing the learning curve to as few as 12 cases [13]. However, it is now accepted that the learning curve issue is much more complex and that individual surgeon results for ORP continue to improve up to 250 cases and beyond [50]. Large series of RALRPs are likely to produce similar conclusions.

The cost effectiveness of RALRP varies from country to country, depending on the health-economic climate. Scales et al. [51] showed the cost equivalence of RALRP with ORP based on 10 cases per week and cost superiority based on 14 cases per week in the United States. However, in many other countries, the high installation and maintenance costs of this technology prevent its widespread implementation, even in high-volume centres.

In a non-randomized comparison of short-term healthrelated quality-of-life scores between ORP and RALRP,
Miller et al. [52] showed a difference of only 1 week in return-to-baseline scores in the physical domain in favour of RALRP and no difference in the mental domain. Further evidence to establish whether RALRP truly improves health-related quality-of-life compared with ORP is needed.

\section{Conclusions}

Regardless of the lack of level I evidence to defend the widespread dissemination of RALRP for the management of localized prostate cancer, there is at least enough nonrandomized evidence to say that the procedure is likely to deliver oncological and functional results on par with ORP. As RALRP has become the preferred approach for radical prostatectomy in many regions, it seems increasingly unlikely that recruitment to randomized trials will be possible. Although questions remain regarding the cost effectiveness of the procedure, it is clear that RALRP is here to stay and that future evolutions of the technology will further consolidate the place of robotic technology in the management of this prevalent condition.

\section{References}

1 Bill-Axelson A, Holmberg L, Ruutu M, Haggman M, Andersson $\mathrm{SO}$, et al. Radical prostatectomy versus watchful waiting in early prostate cancer. N Engl J Med 2005; 352: 1977-84.

2 Bianco FJ Jr, Scardino PT, Eastham JA. Radical prostatectomy: long-term cancer control and recovery of sexual and urinary function ('trifecta'). Urology 2005; 66: 83-94.

3 Schuessler WW, Schulam PG, Clayman RV, Kavoussi LR. Laparoscopic radical prostatectomy: initial short-term experience. Urology 1997; 50: 854-7.

4 Guillonneau B, Vallancien G. Laparoscopic radical prostatectomy: the Montsouris technique. J Urol 2000; 163: 1643-9.

5 Guillonneau B, el-Fettouh H, Baumert H, Cathelineau X, Doublet $\mathrm{JD}$, et al. Laparoscopic radical prostatectomy: oncological evaluation after 1000 cases at Montsouris Institute. J Urol 2003; 169: 1261-6.

6 Touijer K, Eastham JA, Secin FP, Romero OJ, Serio A, et al. Comprehensive prospective comparative analysis of outcomes between open and laparoscopic radical prostatectomy conducted in 2003 to 2005. J Urol 2008; 179: 1811-7.

7 Binder J, Kramer W. Robotically-assisted laparoscopic radical prostatectomy. BJU Int 2001; 87: 408-10

8 Bentas W, Wolfram M, Jones J, Brautigam R, Kramer W, et al. Robotic technology and the translation of open radical prostatectomy to laparoscopy: the early Frankfurt experience with robotic radical prostatectomy and one year follow-up. Eur Urol 2003; 44: 175-81.

9 Rassweiler J, Binder J, Frede T. Robotic and telesurgery: will they change our future? Curr Opin Urol 2001; 11: 309-20.

10 Patel VR, Thaly R, Shah K. Robotic radical prostatectomy: outcomes of 500 cases. BJU Int 2007; 99: 1109-12.

11 Menon M, Shrivastava A, Kaul S, Badani KK, Fumo M, et al. Vattikuti Institute prostatectomy: contemporary technique and analysis of results. Eur Urol 2007; 51: 648-57.

12 Murphy DG, Hall R, Goel R, Costello AJ. Robotic technology in surgery: current status in 2008. ANZ J Surg 2008, in press.

13 Ahlering TE, Skarecky D, Lee D, Clayman RV. Successful transfer of open surgical skills to a laparoscopic environment using a robotic 
interface: initial experience with laparoscopic radical prostatectomy. J Urol 2003; 170: 1738-41.

14 Menon M, Shrivastava A, Tewari A, Sarle R, Hemal A, et al. Laparoscopic and robot assisted radical prostatectomy: establishment of a structured program and preliminary analysis of outcomes. J Urol 2002; 168: 945-9.

15 Menon M, Shrivastava A, Sarle R, Hemal A, Tewari A. Vattikuti Institute Prostatectomy: a single-team experience of 100 cases. J Endourol 2003; 17: 785-90.

16 Menon M, Tewari A, Baize B, Guillonneau B, Vallancien G. Prospective comparison of radical retropubic prostatectomy and robot-assisted anatomic prostatectomy: the Vattikuti Urology Institute experience. Urology 2002; 60: 864-8.

17 Menon M, Hemal AK. Vattikuti Institute prostatectomy: a technique of robotic radical prostatectomy: experience in more than 1000 cases. J Endourol 2004; 18: 611-9.

18 Van Appledorn S, Bouchier-Hayes D, Agarwal D, Costello AJ. Robotic laparoscopic radical prostatectomy: setup and procedural techniques after 150 cases. Urology 2006; 67: 364-7.

19 Rozet F, Jaffe J, Braud G, Harmon J, Cathelineau X, et al. A direct comparison of robotic assisted versus pure laparoscopic radical prostatectomy: a single institution experience. J Urol 2007; 178: 478-2.

20 Han M, Partin AW, Pound CR, Epstein JI, Walsh PC. Long-term biochemical disease-free and cancer-specific survival following anatomic radical retropubic prostatectomy. The 15-year Johns Hopkins experience. Urol Clin North Am 2001; 28: 555-65.

21 Menon M, Tewari A. Robotic radical prostatectomy and the Vattikuti Urology Institute technique: an interim analysis of results and technical points. Urology 2003; 61: 15-20.

22 Mayer EK, Winkler MH, Aggarwal R, Karim O, Ogden C, et al. Robotic prostatectomy: the first UK experience. Int J Med Robot 2006; 2: 321-28.

23 Murphy D, Peters JS, Costello AJ. Operative details and mediumterm oncological and functional outcome of robotic-assisted laparoscopic radical prostatectomy: our first 400 cases with a minimum of 1 year follow-up. BJU Int 2008; 101: 6.

24 Mottrie A, Van MP, De NG, Schatteman P, Carpentier P, et al. Robot-assisted laparoscopic radical prostatectomy: oncologic and functional results of 184 cases. Eur Urol 2007; 52:746-51.

25 Joseph JV, Rosenbaum R, Madeb R, Erturk E, Patel HR. Robotic extraperitoneal radical prostatectomy: an alternative approach. J Urol 2006; 175: 945-50.

26 Atug F, Castle EP, Srivastav SK, Burgess SV, Thomas R, et al. Positive surgical margins in robotic-assisted radical prostatectomy: impact of learning curve on oncologic outcomes. Eur Urol. 2006; 49: 866-71; discussion 871-2.

27 Badani KK, Kaul S, Menon M. Evolution of robotic radical prostatectomy: assessment after 2766 procedures. Cancer 2007; 110: $1951-8$

28 Rassweiler J, Hruza M, Teber D, Su LM. Laparoscopic and robotic assisted radical prostatectomy-critical analysis of the results. Eur Urol 2006; 49: 612-24.

29 Tewari A, Jhaveri J, Rao S, Yadav R, Bartsch G, et al. Total reconstruction of the vesico-urethral junction. BJU Int 2008; 101: 871-7.

30 Savera AT, Kaul S, Badani K, Stark AT, Shah NL, et al. Robotic radical prostatectomy with the "Veil of Aphrodite" technique: histologic evidence of enhanced nerve sparing. Eur Urol 2006; 49: 1065-73.

31 Menon M, Kaul S, Bhandari A, Shrivastava A, Tewari A, et al. Potency following robotic radical prostatectomy: a questionnaire based analysis of outcomes after conventional nerve sparing and prostatic fascia sparing techniques. J Urol 2005; 174: 2291-6, discussion, 2296

32 Kaul S, Savera A, Badani K, Fumo M, Bhandari A, et al. Functional outcomes and oncological efficacy of Vattikuti Institute prostatectomy with Veil of Aphrodite nerve-sparing: an analysis of 154 consecutive patients. BJU Int 2006; 97: 467-72.

33 Goldstraw MA, Dasgupta P, Anderson C, Patil K, Kirby R.
Does robotically assisted radical prostatectomy result in better preservation of erectile function? BJU Int 2006; 98: 721-2.

34 Merilees D, Chabert C, Eden C. Curtain dissection of the lateral prostatic fascia and potency following laparoscopic radical prostatectomy-a veil of mystery. J Urol 2007; 177: 183.

35 Murphy D, Costello AJ. High prostatic fascia release or standard nerve-sparing? A viewpoint from the Royal Melbourne Hospital. J Robotic Surg 2008; 2: 181-5.

36 Ahlering TE, Eichel L, Skarecky D. Evaluation of long-term thermal injury using cautery during nerve sparing robotic prostatectomy. Urology 2008 Feb 28. [Epub ahead of print].

37 Dindo D, Demartines N, Clavien PA. Classification of surgical complications: a new proposal with evaluation in a cohort of 6336 patients and results of a survey. Ann Surg 2004; 240: 205-13.

$38 \mathrm{Hu}$ JC, Nelson RA, Wilson TG, Kawachi MH, Ramin SA, et al. Perioperative complications of laparoscopic and robotic assisted laparoscopic radical prostatectomy. J Urol 2006; 175: 541-6.

39 Fischer B, Engel N, Fehr JL, John H. Complications of robotic assisted radical prostatectomy. World J Urol 2008 Jun 27. [Epub ahead of print]

40 Borden LS Jr, Kozlowski PM, Porter CR, Corman JM. Mechanical failure rate of da Vinci robotic system. Can J Urol 2007; 14 : 3499-501.

41 Zorn KC, Gofrit ON, Orvieto MA, Mikhail AA, Galocy RM, et al. Da Vinci robot error and failure rates: single institution experience on a single three-arm robot unit of more than 700 consecutive robot-assisted laparoscopic radical prostatectomies. J Endourol 2007; 21: 1341-4.

42 Andonian S, Okeke Z, Okeke DA, Rastinehad A, Vanderbrink BA, et al. Device failures associated with patient injuries during robotassisted laparoscopic surgeries: a comprehensive review of FDA MAUDE database. Can J Urol 2008; 15: 3912-6.

43 Tewari A, Srivasatava A, Menon M. A prospective comparison of radical retropubic and robot-assisted prostatectomy: experience in one institution. BJU Int 2003; 92: 205-10.

44 Ahlering TE, Woo D, Eichel L, Lee DI, Edwards R, et al. Robotassisted versus open radical prostatectomy: a comparison of one surgeon's outcomes. Urology 2004; 63: 819-22.

45 Webster TM, Herrell SD, Chang SS, Cookson MS, Baumgartner $\mathrm{RG}$, et al. Robotic assisted laparoscopic radical prostatectomy versus retropubic radical prostatectomy: a prospective assessment of postoperative pain. J Urol 2005; 174: 912-4.

46 Farnham SB, Webster TM, Herrell SD, Smith JA Jr. Intraoperative blood loss and transfusion requirements for robotic-assisted radical prostatectomy versus radical retropubic prostatectomy. Urology 2006; 67: 360-3.

47 Nelson B, Kaufman M, Broughton G, Cookson MS, Chang SS, et al. Comparison of length of hospital stay between radical retropubic prostatectomy and robotic assisted laparoscopic prostatectomy. J Urol 2007; 177: 929-31.

48 O’Malley PJ, Van AS, Bouchier-Hayes DM, Crowe H, Costello AJ. Robotic radical prostatectomy in Australia: initial experience. World J Urol. 2006; 24: 165-70.

49 Smith JA Jr, Chan RC, Chang SS, Herrell SD, Clark PE, et al. A comparison of the incidence and location of positive surgical margins in robotic assisted laparoscopic radical prostatectomy and open retropubic radical prostatectomy. J Urol 2007; 178: 2385-9.

50 Vickers AJ, Bianco FJ, Serio AM, Eastham JA, Schrag D, et al. The surgical learning curve for prostate cancer control after radical prostatectomy. J Natl Cancer Inst 2007; 99: 1171-7.

51 Scales CD Jr, Jones PJ, Eisenstein EL, Preminger GM, Albala DM. Local cost structures and the economics of robot assisted radical prostatectomy. J Urol 2005; 174: 2323-9.

52 Miller J, Smith A, Kouba E, Wallen E, Pruthi RS. Prospective evaluation of short-term impact and recovery of health related quality of life in men undergoing robotic assisted laparoscopic radical prostatectomy versus open radical prostatectomy. J Urol 2007; 178: 854-9. 